\title{
La agenda oculta: resistencias del patriarcado a la investigación en comunicación
}

DoI: 10.15213/redes.n11.p8

LUCÍA BENÍTEZ EYZAGUIRRE

Tan intrincado y complejo resulta el proceso de sacudir la realidad para despojarla del patriarcado que incluso desde los enfoques más brillantes y poderosos, desde las iniciativas más ambiciosas y globales, a duras penas se logran resultados palpables. Las propuestas que surgen del cruce de la comunicación y el género no han faltado en las dos últimas décadas, pero sin haber llegado a calar en la agenda pública de la gran mayoría de países, sin que la práctica cotidiana las haya consolidado, sin que se haya dado el paso de la comunicación a la acción, de la teoría a la práctica, de la investigación a la transformación... Y esto pese a ser éste un campo tan poderoso, pues es el de la teorización y la investigación sobre la construcción del discurso, de las mediaciones, de la semiótica, de los imaginarios, de la representación, de la estructura mediática, en fin, de campos de interés y peso para el avance científico.

La Alianza Global de Medios de Comunicación y Género (GAMAG), creada en 2013 por la UNESCO para actualizar iniciativas anteriores, es en cierto sentido la constatación del escaso progreso experimentado en este ámbito, pues todavía hoy la equidad en los medios y en la comunicación muestra tan sólo avances mínimos y muy lentos. Los resultados, quince años después de la iniciativa "Las mujeres hacen la noticia" y cuando se han cumplido dos décadas de la Plataforma de Acción Beijing, son demoledores: sólo una cuarta parte de las personas que se representan o que se expresan con voz propia en los medios de comunicación son mujeres. La cuestión de género tiene un peso testimonial en los contenidos mediáticos, de poco más del cinco por ciento, y eso que resulta clave para comprender las transformaciones y cambios, así como generar conciencia de la desigualdad de género.

A pesar de que las transformaciones sociales y la complejidad de los procesos sociales y políticos se muestran de una forma más clarificadora a través de la intersección entre el género y la comunicación, la resistencia y el anclaje de conceptos fundamentales a contextos del pasado tienen tal fuerza que frenan un avance significativo de este campo tan innovador. $Y$ es justo ahora cuando hay que recordar que los ideales de la modernidad 
se construyeron a partir del sistema económico y social propio del poder patriarcal, con disgregación entre lo público y lo privado, que estructuró un orden 'natural' todavía hoy operante. De hecho, es la lógica de la exclusión más difícil de neutralizar, pues se reproduce más allá del ámbito privado: en el trabajo, en el sistema de clases, en las diferencias étnicas, en cualquier contexto social, actuando como un método infalible de jerarquización y subordinación, pues se encuentra inserto en la lógica cultural que opera en paralelo a todo el sistema económico, político y social.

En la cultura está también la radical resistencia a las transformaciones; la importancia del orden comunicacional y cultural para operar a través de restricciones simbólicas en lo cotidiano como un sistema de dominio (BOURDIEU, 1988), ha llevado a atender al análisis de las representaciones sociales a partir de las cuales elaboramos y reelaboramos nuestro repertorio de imaginarios sociales y mundos posibles como elementos constitutivos de la cultura, de los valores colectivos, de la transformación de las mentalidades. Ahí se registra el peso de la representación de la mujer como temática central de lo simbólico (BOURDIEU, 1999) y como objeto de la violencia simbólica con la que se la subordina.

La comunicación es y ha sido el canal de una narrativa discriminatoria, de la naturalización de la diferencia en que se apoya el sexismo y el discurso etnográfico, a partir de todo un repertorio de variantes del esencialismo genetizado, del respaldo científico construido contra las personas, del enquistamiento de una lógica discriminatoria que en paralelo instituyó una jerarquía de género y otra racial, una biologización del pensamiento social (WIERVIORKA, 1992).

Todo ello para vislumbrar de nuevo, y todavía con más fuerza, de forma más intrincada y enraizada, que la categoría género resulta más difícil de erradicar porque opera por encima de las culturas, porque se hace invisible en la lógica contradictoria con la que gestionamos otras diferencias (ORTNER, 1979). Por tanto, estamos ante la enorme dificultad de deconstruir el género (BUTLER, 1990) por encima de la biología, al tratar de desentrañar la lógica de oposición que consagró la heterosexualidad como norma, que nos llevó a entender el sexo como una categoría política y esencial de presentación ante lo social y colectivo.

La resistencia a los cambios, y la dificultad para desmantelar estas estrategias que operan contra las personas en el contexto de las transformaciones sociales y comunicativas, muestran cómo la cultura se ha hecho fuerte, cómo llega incluso bajo las mismas lógicas y con la misma potencia a controlar el propio cambio que contribuyó a transformar. Es tanto como entender que 
también la cultura opera también a modo de código genético, si como éste se utiliza para justificar una esencia inmutable y natural. $Y$ aunque resulte contradictorio, la fuerza de la construcción cultural sobre el género también nos debería permitir mostrar los sesgos ocultos que se insertan en los discursos, los esquemas universales del prejuicio hacia las mujeres, las constricciones sociales, las razones económicas y las formas de poder. Es decir, la categoría género y su análisis muestran una dimensión compleja, diversa y amplia de desarticular las formas de poder, los repartos inequitativos y desiguales que se gestionan en interés propio.

Butler (1990) lleva décadas en ese empeño, en el desnaturalizar las construcciones culturales ocultas bajo los conceptos y las normas para buscar alternativas por la vía preformativa, como una posibilidad dinámica de entender la identidad en este mundo líquido, más allá de cualquier código binario. Las estrategias del poder han arraigado en diferentes dimensiones de la comunicación, de la experiencia y de las interacciones. Para desentrañarlas hay que buscar otras formas de analizar y comprender el poder, de producir nuevas representaciones discursivas que permitan transgredir las antiguas divisiones, ahora con inclusión de las emociones y de la ambivalencia, del dualismo, de la diversidad o la subjetividad. Sólo así se podría lograr una nueva productividad y resiliencia a partir de representaciones negativas, de la erosión cultural que se puede transformar en instrumento de resistencia (HALL, 1997). A fin de cuentas, en las formas de resistencia hay procesos de negociación y de reconstrucción cultural y de la diversidad, una oportunidad de analizar de forma creativa la construcción de la subalternidad, otro modo de subversión.

A partir de las formas de dibujar la realidad, de remarcar estereotipos, de anclarnos al pasado e impedir el avance, se puede trazar otra lectura de esta cuestión compleja, al margen del relato lineal y casual que a menudo deja demasiados aspectos sin resolver, demasiadas lagunas. Toca repasar dónde están los fundamentos de una construcción de la realidad que se resiste a los análisis y a las propuestas de acción llenas de conciencia y de militancia.

1. Las políticas públicas, las intervenciones sociales y la planificación han de tener en cuenta la importancia del papel de la comunicación tanto en la construcción de o social y público, como en el desarrollo sostenible y las oportunidades de transformación social y económica. Por tanto, el diseño y el análisis de este campo deben asumir la perspectiva de género como el único enfoque posible para una sociedad diversa e inclusiva. 
2. La representación y la presencia de las mujeres en los medios, con la misma inequidad de hace décadas, a través de los mismos estereotipos y sesgos, pone de relieve el campo de poder que sigue dominando el ámbito de lo mediático, tanto en la producción como en la reproducción del discurso.

La estructura mediática, como campo complejo de construcción de los poderes económicos y políticos, reproduce la desigualdad en las redacciones, en el reparto del poder, en la toma de decisiones, en la agenda... Por supuesto, hay mujeres en las redacciones - son mayoría-, hay becarias, pero se encuentran muy pocas en puestos de edición, de dirección. Resulta más difícil investigar y objetar a la estructura de los medios, a su financiación, a sus políticas laborales o a sus sistemas internos de exclusión que a sus políticas de representación, de reproducción. No hay más que recordar que la producción científica ha dado muy pocos estudios sobre las relaciones laborales en los medios de comunicación, sobre las rutinas de producción y sobre los procesos internos de los medios y muchos sobre las representaciones mediáticas.

3. En la representación y producción, el análisis de la desigualdad de género se centra siempre en el terreno simbólico, como un espacio crítico que busca la transformación sólo de las formas, no de las estructuras. Se analiza la visibilidad ante la opinión pública, los modos de construcción de las identidades subjetivas y colectivas, los cambios culturales y las diferencias; se permite la denuncia de la desigualdad simbólica, las prácticas mediáticas, pero se aleja de la acción y de la transformación, del empoderamiento comunicativo, de la autonomía necesaria para construir alternativas a estos sistemas de representación delegados, a que te mencionen pero que no cuenten contigo, a consagrar el ejercicio de la influencia como un campo único de la comunicación. Mientras sigamos en este terreno no avanzamos en la construcción de la comunicación horizontal y participativa, en el diálogo para la comprensión de la igualdad y la pluralidad.

4. El debate sobre la desigualdad en la representación oculta (o al menos desplaza) el análisis de las causas de la ausencia de contenidos en los medios sobre las propias diferencias de género, sobre la teoría de género o sobre los modos de desentrañar las formas ocultas de la desigualdad en las relaciones, en las sociedades, en las comunidades, en las familias. De nuevo aquí se desplaza el trabajo imprescindible para el avance social, que se apoya en la alfabetización mediática y digital como marco de comprensión del retrato social, y que está orientada al empoderamiento sobre las formas en que se comunica 
el sentido y se forja el conocimiento sobre el género, tanto en la expresión comunicativa como en la construcción del lenguaje, que es el trasmisor del propio mensaje. Se trataría pues de avanzar más allá de las políticas lingüísticas y del lenguaje no sexista. Este modelo constructivista de lo social, que tiene su influencia y calado, es una herramienta - pero no la única-que puede contribuir al avance de una comprensión de la complejidad y diversidad, a la solución de los problemas y al paso de la comunicación a la acción. De hecho, en la mayoría de sus formas, se remite a la construcción del género dicotómico.

5. La investigación sobre género y comunicación es testimonial y en ocasiones anecdótica, enfocada en muchos casos desde los intereses y temáticas de esta construcción del mundo que venimos definiendo. El cruce epistemológico debería permitir la revisión conceptual de la investigación a partir de la construcción social del sentido, priorizando las metodologías cualitativas, la conexión con la acción, y los contextos locales y privados. La evidencia muestra que es el poder como sistema universal el que presenta la misma lógica en todas las sociedades y todos los ámbitos de la vida de las mujeres. Así, no resulta difícil entender que los sistemas de conocimiento ya tienen en sí mismos y en su origen el conflicto de género inscritos en su esencia, para comprender que hay que reescribirlos y analizar sus causas de forma permanente (PÉREZ OROZCO, 2002). En el terreno investigativo se registra un desenfoque entre la perspectiva de género y la coherencia metodológica necesaria, en los instrumentos, técnicas y herramientas que parten del género para el análisis y evaluación de la realidad. Como objeto de investigación, no se suele atender al efecto de la comunicación cuando se emite y se planifica por y para mujeres, así como tampoco la importancia y el impacto de los movimientos sociales de mujeres o desde la perspectiva de género, ni la percepción y las transformaciones de los movimientos de mujeres, etc. De la misma forma, se puede resumir que la investigación en comunicación para el desarrollo se ha centrado en muchos casos en el sistema de medios y en el poder, pero no así en esta estructura como forma de violencia, de violencia simbólica y real.

6. El escenario tecnológico y digital en que tienen lugar los procesos de comunicación, así como el papel que las TIC juegan en el presente y se esbozan para el futuro, hacen necesario repensar su importancia, y no sólo porque se trata de otro campo para la representación de la desigualdad. En Beijing se planteaba la necesidad de garantizar el acceso de las mujeres a las 
tecnologías, a través de la conectividad y la formación en el uso tecnológico. Se trata de mucho más, se trata del empoderamiento que, gracias a la digitalización, permite una nueva agenda de derechos. La cuestión está en que la tecnología es un campo de poder y en por qué, de nuevo, las mujeres no están presentes en los debates, en los diseños y en la organización de la sociedad de la información, es decir, en la toma de decisiones sobre la conectividad, sobre la capacidad redistributiva de la misma, sobre los lazos y relaciones que permiten otra comprensión del valor de lo social, en la dimensión política, ni tampoco en la creación de alternativas y en el cultivo del imaginario tecnológico. La canalización de estos procesos, el diseño de la tecnología serán determinantes en las decisiones sobre las políticas del futuro.

La brecha de género en el acceso y formación tecnológica profundiza otras brechas existentes en calidad de vida, educación, salud o cultura, en definitiva en los derechos fundamentales como el derecho al trabajo o el de tener una cultura compartida e interactiva continua, que es el escenario de las redes de solidaridad, de la renegociación de las normas sociales de género. En este marco se produce también la reducción de costes de muchos intercambios, la creación de espacios comunes, la coordinación, el uso más eficaz del tiempo, la difusión de logros en materia de igualdad, la cooperación en iniciativas, la expresión de la voz propia, el contacto emocional, el acceso a mercados, la difusión de sus actividades, el asesoramiento y el emprendimiento.

En la lógica comunicativa, la transformación es fruto del pensamiento, del análisis y de la acción. Tras décadas de planteamientos y proyectos, la acción está sin duda en las prácticas comunicativas, desde la capacitación y la información, en el núcleo del compromiso social del desarrollo inclusivo. Todo ello en un contexto en el que los cambios tecnológicos permiten prácticas empoderadas, autocomunicativas, en la lógica distribuida y colaborativa del mundo digital

Las políticas públicas y los enfoques transformadores se mantienen encerrados en la misma lógica del patriarcado, ocupados en lo objetual y reproductivo como campos visibles de sus estrategias, mientras se olvida de forma continuada el núcleo duro de este sesgo, que se encuentra en el mismo corazón de la producción mediática, en la visión subjetiva y personal en la que se recrean y consolidan los sesgos, para abrir una senda hacia otras lógicas y nuevas formas de entender y percibir la realidad. 


\section{BIBLIOGRAFÍA}

BOURDIEU, P. (1988). La distinción. Criterios y bases sociales del gusto. Madrid: Taurus.

BOURDIEU, P. (1999). La dominación masculina. Madrid: Anagrama.

BUTLER, J. (1990). Gender Trouble: Feminism and the Subversion of Identity. New York and London: Routledge.

HALL, S. (Ed.) (1997). Representation. Cultural Representations and Signifying Practices. Londres: Sage.

MORIN, E. (2000). Identidad nacional y ciudadanía. En Gómez García, P. (Coord.) (2000), Las ilusiones de la identidad (pp. 17-28). Madrid: Ediciones Cátedra.

ORTNER, S. (1979). ¿Es la mujer al hombre lo que la Naturaleza es a la Cultura? En Harris, Olivia y Kate Young (Comp.), Antropología y feminismo (pp. 109-131). Barcelona: Anagrama. http://www.museo-etnografico.com/ pdf/puntodefuga/150121sherryortner.pdf

WIEVIORKA, M. (1992). El espacio del racismo. Barcelona: Paidós. 